\title{
CELEBRIDADES, MARCAS E CONSUMO: QUAIS ATRIBUTOS DOS FAMOSOS FORTALECEM UM PRODUTO NO MERCADO?
}

\author{
Celebrities, brands and consumption: \\ What attributes of celebrities strengthen a product in the Market?
}

Celebridades, marcas y consumo:

¿Qué atributos de los famosos fortalecen un producto en el mercado?

\author{
Andrea Costa do Nascimento ${ }^{1}$ \\ Clodilde Perez ${ }^{2}$ \\ Diego Antonio de Oliveira ${ }^{3}$ \\ Karla Patriota Bronsztein ${ }^{4}$
}

\section{Resumo}

Em um país carente de estudos e pesquisas sobre o efeito das celebridades no consumo, o presente artigo revela as principais descobertas de uma aprofundada pesquisa sobre celebridades no Brasil, feita pela Ipsos Media CT, encomendada pelo núcleo de celebridades da Revista Contigo! da Editora Abril. O estudo foi desenvolvido para revelar um panorama real do cenário no qual as celebridades circulam influenciando o consumo, a publicidade, a economia e os comportamentos brasileiros.

Palavras-chave: celebridades, consumo, Brasil, pesquisa, atributos dos famosos.

\begin{abstract}
In a country that lacks studies and surveys about the effect of celebrities on consumption, this article presents the main findings from an in-depth study on celebrities in Brazil, carried out by Ipsos Media CT for the Contigo! Magazine nucleus of celebrities at Abril Publisher. The study was designed to understand the setting in

\footnotetext{
${ }^{1}$ Graduada em Estatística pela Faculdade Capital e pós-graduada em Marketing pela FAAP. Gerente de Inteligência e Pesquisa de Mercado da Editora Abril. E-mail: Andrea.Costa@abril.com.br

${ }^{2}$ Livre-Docente em Comunicação pela USP. Doutora em Comunicação e Semiótica e Mestre em Administração de Marketing pela PUC SP. Professora do programa de Pós-graduação em Ciências da Comunicação. E-mail: cloperez@terra.com.br

${ }^{3}$ Mestrando em Comunicação pela Cásper Líbero. Account Director do Ipsos Marplan. E-mail: Diego.Oliveira@ipsos.com

${ }^{4}$ Doutora em Sociologia e mestre em Comunicação pela UFPE. Professora do PPGCOM-UFPE. E-mail: k.patriota@gmail.com
} 
Celebridades, marcas e consumo: quais atributos dos famosos fortalecem um produto no mercado?

de Andrea Costa do Nascimento, Clodilde Perez, Diego Antonio de Oliveira e Karla Patriota Bronsztein

which celebrities circulate, influencing consumption, advertising, the economy and behavior in Brazil.

Keywords: celebrities, consumption, Brazil, research, attributes of celebrities.

\section{Resumen}

En un país carente de estudios y pesquisas sobre el efecto de las celebridades en el consumo, el presente artículo revela los principales hallazgos de una profunda investigación sobre celebridades en Brasil, hecha por Ipsos Media CT, encomendada por el núcleo de celebridades de la Revista Contigo! de la Editora Abril. El estudio fue desarrollado para revelar un panorama real del escenario en el cual las celebridades circulan influenciando el consumo, la publicidad, la economía y los comportamientos brasileños.

Palabras-clave: celebridades, consumo, Brasil, pesquisa, atributos de los famosos.

\section{INTRODUÇÃO}

De forma geral, não causa estranheza a afirmação de que o arquétipo da celebridade está substituindo o arquétipo do herói na sociedade contemporânea (HOLT, 2004; MARK \& PEARSON, 2002), tão somente porque há uma elevação peculiar do status da celebridade na sociedade midiatizada, e mesmo que entre "heróis ${ }^{5}$ e celebridades $^{6,}$ encontremos diferenças identitárias, como a apontada por Boorstin (1962), de que um herói distinguia-se por seus feitos e uma celebridade, por sua imagem ou marca, a essência da percepção está na grandiosidade inserida no conceito. "Enquanto o herói era um grande homem, a celebridade é um grande nome".

O que vale destacar, contudo, é que na nossa sociedade midiatizada e de consumo, produtos são vendidos como extensões das celebridades. Inclusive, boa parte destas são até mesmo criadas para durarem pouco e assim dialogarem com a acelerada rotatividade da busca por novidades de consumo. Não é a toa que certas celebridades,

\footnotetext{
${ }^{5}$ O Herói vive para "redimir a sociedade de seus pecados e/ou suas falhas", vive para os outros, enquanto a celebridade vive somente para si. (HELAL 1998). O herói acredita que tem uma missão a cumprir. Ele deve domar o cotidiano e viver na esfera do extraordinário.

${ }^{6}$ A celebridade (exceção das que se dedicam às causas sociais) não tem missão além de se expor na mídia e viver na esfera do cotidiano ostentatório (PENA 2002, : 148).
} 
Celebridades, marcas e consumo: quais atributos dos famosos fortalecem um produto no mercado?

de Andrea Costa do Nascimento, Clodilde Perez, Diego Antonio de Oliveira e Karla Patriota Bronsztein

tratadas como marcas, apresentam características típicas de produtos do contemporâneo como efemeridade e perecibilidade (MATTA, 2009).

O fato é que, mesmo existindo alguns estudos e pesquisas no Brasil, autores como Freire, Behling \& Reinert (2010), Andrade, Mazzon \& Kartz (2006) e Silveira, Marcon \& Nascimento (2007) esclarecem que o assunto ainda é pouco explorado no país. Por outro lado, a questão, já vem sendo discutida por vários autores internacionais com maior nível de aprofundamento e montagem de modelos para a análise do fenômeno, como os de Shimp (2003) ${ }^{7}$, de Alsmadi (2006) ${ }^{8}$ e de Patel (2009) ${ }^{9}$ - o que evidencia que a temática apresenta um alto grau de complexidade e necessitava ser melhor estudada.

Nesse complexo cenário, carente de uma abordagem mais empírica, o presente artigo revela as principais descobertas de uma aprofundada pesquisa sobre celebridades no Brasil, feita pela Ipsos Media CT, encomendada pelo núcleo de celebridades da Revista Contigo! da Editora Abril. O estudo foi desenvolvido para revelar um panorama real do cenário no qual as celebridades circulam influenciando o consumo, a publicidade, a economia e os comportamentos brasileiros. A pesquisa foi realizada durante o $1^{\circ}$ semestre de 2012 e retrata o cenário naquele momento, já que este pode ser metaforizado como um organismo vivo e que, por conseguinte, sofre transformações de acordo com os acontecimentos na vida pessoal e profissional de cada celebridade.

\section{O QUE É UMA CELEBRIDADE?}

Celebridade é, por definição, uma pessoa amplamente reconhecida pela sociedade. A palavra deriva do latim celebritas que quer dizer "famoso, celebrado". A fama e o reconhecimento são os principais fatores para o status de uma celebridade, mas

\footnotetext{
${ }^{7}$ Criador do "TEARS", modelo teórico desenvolvido para analisar a eficiência da celebridade como portavoz do produto e sua influência no comportamento do consumidor. As variáveis propostas fornecem diretrizes para tomada de decisão de marketing na contratação de uma celebridade. Tal modelo foi adaptado para esta pesquisa.

${ }^{8}$ Que realizou um estudo na Índia e propôs uma ampliação das variáveis do modelo TEARS, adicionando fatores de análise do ponto de vista da empresa, a saber: Credibilidade da celebridade; Sintonia entre celebridade e audiência; Sintonia entre celebridade e marca; Poder de atração da celebridade; Custos envolvidos; Dificuldades ou facilidades de trabalho; Fator de saturação; e Fator de risco.

${ }^{9}$ Este último desenvolveu um modelo com 14 pontos a serem avaliados no uso da imagem de uma celebridade, cujos aspectos podem ser considerados similares ao modelo anterior. Também se agregam fatores para avaliação da empresa e desdobramentos dos fatores originais do modelo TEARS.
} 
Celebridades, marcas e consumo: quais atributos dos famosos fortalecem um produto no mercado?

de Andrea Costa do Nascimento, Clodilde Perez, Diego Antonio de Oliveira e Karla Patriota Bronsztein

não são suficientes. Para ser uma celebridade, a pessoa deve ter uma presença ativa, pelo menos na mídia, oferecendo algum significado para pelo menos um grupo de pessoas.

Como "ingredientes desse sucesso", os estudos de base da presente pesquisa (Análise Semiótica) nos conduziram para seis características básicas, a saber: 1. Ser admirável (destacar-se em algo, ter talento); 2. Dar bons exemplos e ter valores (não se envolver em escândalos, ser honesto, mostrar que tem bom caráter); 3. Criar empatia e ter carisma (ser simpático, seguro); 4. Ter uma trajetória de vida de sucesso e equilibrada (conseguir sucesso na vida pessoal e na profissional); 5. Ter equilíbrio (não se expor demais, mas não ser distante nem arrogante); e 6. Ser solidário (mostrar que se importa com o mundo, que quer ajudar, não ser egoísta).

Soma-se a tais características a visão apresentada no início deste artigo, já que na definição de celebridade, percebe-se certa aproximação com o "arquétipo do herói", desenvolvida por Jung (1998), que define o herói, e aqui o fazemos de forma bem generalizada, como um personagem que possui características e valores tidos com um modelo a ser seguido. Isso é relevante porque, entre as nossas descobertas, uma das mais "palpáveis" é a de que as consumidoras entrevistadas na pesquisa enxergaram, amplamente, esse "heroísmo" nas celebridades. Contudo, vale ressaltar que embora as celebridades catalisem a atenção e preencham o imaginário coletivo, há uma concreta diferenciação na identificação com os heróis, uma tradição da cultura ocidental, como pontua Helal (1998 apud PENA 2002) recorrendo às interpretações de Cambpell (1993) e Morin (1989) para demarcar a diferença entre o herói e a celebridade: enquanto o primeiro se funda no coletivismo, a base fundamental da celebridade é o individualismo.

Ainda numa dimensão conceitual, dentro do "ecossistema" que abriga os mais diversos tipos de celebridades, os nossos estudos de base evidenciaram a caracterização de três grandes grupos: a) Celebridade-Ídolo; b) Personagem Célebre; e c) Personalidade Célebre.

As celebridades-ídolo compõem o grupo das que atingem o nível de "ídolos". São pessoas que conquistaram algo extraordinário. Sejam feitos políticos, esportivos, profissionais ou pessoais. Essas pessoas são notáveis e praticamente intocáveis. Funcionam no ecossistema célebre como catalisadores sociais, são memoráveis, tem 
Celebridades, marcas e consumo: quais atributos dos famosos fortalecem um produto no mercado?

de Andrea Costa do Nascimento, Clodilde Perez, Diego Antonio de Oliveira e Karla Patriota Bronsztein

carreiras sólidas e representam pelo menos uma forte característica (talento, bondade etc).

Já os personagens célebres fazem parte do grupo de personagens tangíveis ou abstratos que se destacam por seus atributos, projeção social ou conteúdo. Seja um personagem de uma história em quadrinhos, de uma novela ou um super-herói, todos têm em comum o fato de serem figuras criadas, ficcionais. São altamente afetivas e tem como principais características a efemeridade e a instantaneidade.

O terceiro grupo que completa o ecossistema das celebridades é o denominado de personalidades célebres. São pessoas reais que se destacam por seus atributos positivos e negativos. São reconhecidas por seus feitos, celebradas por suas virtudes e totalmente dependentes da mídia. Tem amplo espectro e abrangem desde políticos até figuras do cenário artístico, jornalistas, ditadores, criminosos, assassinos entre outros.

Obviamente a exposição e a ampliação desse ecossistema são potencializadas pela mídia, principalmente numa sociedade que hoje parece estar carente de ídolos e heróis. Por isso, vemos a atenção midiática voltada para as celebridades, que vão consolidando sua imagem no pêndulo entre o talento profissional e sua vida privada. Soma-se a isso o fato de que, se no passado era preciso ler a biografia de uma estrela para conhecer passagens de sua intimidade (PENA 2002: 155), hoje, esse papel cabe à imprensa, principalmente às revistas que, dia a dia, constroem seus "álbuns familiares".

Por fim, as celebridades existem a partir da tríade hipercompetência midiática, identificação com o público e interesses comerciais, alicerçada num limiar ambíguo, e que é quadrangulado por "informação versus entretenimento" e "realidade versus ficção".

\section{METODOLOGIA E ESTRUTURA DA PESQUISA}

A partir dos interesses da Editora Abril, a Ipsos realizou um estudo multidimensionado, combinando diferentes técnicas e abordagens, em três principais vetores e desenvolvendo a pesquisa em quatro etapas.

O primeiro vetor do estudo foi constituído pela obtenção de conhecimento, através de estudos de base, por meio do mapeamento semiótico das celebridades no consumo das marcas (Análise Semiótica) e do levantamento e sistematização do 
Celebridades, marcas e consumo: quais atributos dos famosos fortalecem um produto no mercado?

de Andrea Costa do Nascimento, Clodilde Perez, Diego Antonio de Oliveira e Karla Patriota Bronsztein

conhecimento científico e mercadológico sobre o tema (Desk Research). Tal conhecimento forneceu subsídios para as demais etapas do estudo: inputs para roteiros e questionários e levantamento de hipóteses, além de direcionamentos para a segmentação.

Com a análise semiótica foi possível construir o "Universo de sentido da Celebridade" por meio da análise e sistematização de seus signos expressivos na cultura brasileira, tais como manifestações verbais, cromáticas, icônicas, indiciais, sensoriais, contextos espaciais etc. Além disso, conseguimos entender a potência comunicativa das celebridades, por meio do mapeamento semiótico publicitário. Respondemos a perguntas como: A que estão associadas? Quais categorias e marcas estão mais fortemente vinculadas às celebridades? Quais sentidos são aportados por meio do uso das celebridades?

Com a desk research identificamos o quanto e como o tema tem sido tratado na produção científica nacional e internacional e pelas empresas em geral, além de conseguir sistematizar os principais aprendizados obtidos nos estudos de interesse. Dessa forma, os resultados dessa etapa foram estruturados sobre 5 pilares: 1. Contemporaneidade (abordagem social e antropológica); 2. O Papel das celebridades no universo de consumo (pesquisas de mercado e pesquisas acadêmicas); 3. Comportamentos recorrentes e perfil do público "consumidor de celebridades" (pesquisas de mercado e textos acadêmicos); 4. Estratégias de Marcas envolvendo Celebridades (como o mercado tem usado as celebridades - através de publicações na mídia); e 5. Direcionamentos para formulação de um mapa de celebridades (insights resultantes da própria desk research).

O segundo vetor da pesquisa foi constituído por estudos qualitativos com consumidores e profissionais de publicidade. Entre os consumidores foram investigados 10 grupos formados por mulheres de 25 a 45 anos, Classe AB1(Critério Brasil $\mathrm{ABEP}^{10}$ ), moradoras de São Paulo e Rio de Janeiro (mercados que apresentam relevantes índices de consumo) e foram feitas 5 entrevistas pessoais, em profundidade, com mulheres de 25 a 45 anos, classe A+(Critério Brasil - ABEP), também moradoras

\footnotetext{
${ }^{10}$ Modelo matemático desenvolvido em 2008, trata da posse de bens não voláteis (bens com consumo estabilizado). Cada pesquisa realizada por um instituto possui o sistema de pontuação do Critério Brasil. O modelo é replicado mas, dependendo da área a ser mensurada, seus dados serão diferentes.
} 
Celebridades, marcas e consumo: quais atributos dos famosos fortalecem um produto no mercado?

de Andrea Costa do Nascimento, Clodilde Perez, Diego Antonio de Oliveira e Karla Patriota Bronsztein

das mesmas cidades e decisoras das marcas de diferentes categorias, de acordo com o momento de vida (estudantes, jovens solteiras, adultas sem filhos, mães recentes, maduras). Com isso, pudemos aprofundar as questões trazidas pelos estudos de base pela ótica das consumidoras, conseguimos validar o conceito de celebridade, identificar e associar as celebridades a atributos, ambientes e locais onde combinam sua presença, incluindo as plataformas de mídia e os segmentos de consumo e marcas relacionadas.

No segundo vetor também realizamos entrevistas em profundidade com 5 profissionais do mercado (3 diretores de marketing de multinacionais de bens de consumo, 1 Chief executive officer - CEO (diretor geral) de agência de publicidade e 1 diretora de comunicação de um veículo (televisão), todos reconhecidos pela ampla atenção e conhecimento do tema e que participaram de projetos e/ou campanhas envolvendo celebridades. Assim, obtivemos o entendimento das escolhas de representação de marca, pela ótica dos profissionais e das marcas. Identificamos, de igual forma, os grandes anseios com relação às celebridades no mundo da propaganda e do consumo e o tamanho e movimentação desse mercado.

$\mathrm{O}$ terceiro vetor da pesquisa foi constituído por estudos quantitativos com consumidoras por meio de web survey (entrevistas individuais via web, com aplicação de questionário de duração máxima de 30 minutos e 2 perguntas abertas). Essa etapa buscou promover uma leitura na população de mais de 6.000 mulheres brasileiras de 18 a 50 anos, classe ABC (Critério Brasil - ABEP), leitoras de Contigo! e demais revistas de celebridades e não leitoras. Pudemos assim identificar quem é o fã de cada celebridade, uma espécie de RG (registro geral) do fã (declaração e confirmação por atitude) e mapeamento de seus valores, interesses e consumo.

Além disso, quantificamos a relação de celebridades com seus atributos, ambientes, segmentos e categorias de produtos, segmentos de conteúdo editorial (cardápio da redação) - o que nos possibilitou gerar uma segmentação de celebridades por atributo e grupos que, em um primeiro momento, chamamos de "constelações", denominadas posteriormente (após o agrupamento final) de "ecossistemas" para cada segmento, considerando ambientes, categorias e marcas. Para isso, realizamos duas segmentações distintas (single axis), uma de consumidores e uma de celebridades.

No âmbito analítico, as duas segmentações foram associadas, a fim de definirmos uma relação entre grupos (segmentos) de consumidoras e grupos de 
Celebridades, marcas e consumo: quais atributos dos famosos fortalecem um produto no mercado?

de Andrea Costa do Nascimento, Clodilde Perez, Diego Antonio de Oliveira e Karla Patriota Bronsztein

celebridades nos diferentes meios de mídia. Também conseguimos identificar o tamanho do mercado (pessoas que declaram a compra motivada por ações e comportamentos das celebridades) e quais celebridades tinham maior participação neste mesmo mercado.

A última etapa do $3^{\circ}$ vetor se constituiu em análises especiais, realizadas após o desenvolvimento do questionário, que nos possibilitaram levantar informações adicionais a partir da base de dados já existente nos estudos Ipsos - Marplan, com foco no consumo midiático, e contribuíram para a obtenção de conhecimento relevante sobre o universo das celebridades.

\section{O PODER DE INFLUÊNCIA DAS CELEBRIDADES}

Como os principais objetivos da propaganda é atingir o nível máximo, a ação, a atenção e a conversão, o que pode gerar uma mudança positiva de estado (conhecimento e/ou compra), as celebridades na atualidade podem atuar em diferentes esferas para isso. Diversos estudos nacionais e internacionais tem comprovado tal circunstância e a sistematização que fizemos em nossos estudos de base revelaram, pelo menos 7 espaços de atuação mais importantes: a) aumento do nível de atenção à mensagem; b) crescimento do recall da propaganda e da marca; c) transferência do significado simbólico da celebridade para a imagem da marca; d) aumento da percepção de valor; e) indução à experimentação; f) associação de seus atributos à marca; e g) geração de preferências e intenção de compra.

Tais espaços de atuação promovem a movimentação constante e crescente desse mercado que lança mão das celebridades para gerar consumo. Por isso, por meio da pesquisa, também buscamos entender os motivos que levam as marcas a usarem as celebridades como endossantes de seus produtos.

Vale destacar que atração (atratividade da celebridade endossante) e recall são as condições imediatas, enquanto que na condição de reconhecimento da celebridade, se verifica uma alta influência para o consumo - quanto mais se conhece a celebridade, mais se compra o que ela anuncia. Celebridades com traços como atratividade, reconhecimento e uso real do produto, podem ainda desencadear processos cognitivos e/ou afetivos mais duradouros para a marca. Com esse mapeamento, pudemos 
Celebridades, marcas e consumo: quais atributos dos famosos fortalecem um produto no mercado?

de Andrea Costa do Nascimento, Clodilde Perez, Diego Antonio de Oliveira e Karla Patriota Bronsztein

identificar quais atributos fazem determinada celebridade ser um bom embaixador, qual o seu poder de endosso para uma marca e com quais segmentos ela melhor se relaciona. Foi necessário, portanto, estudar as teorias e identificar aquela aplicável ao consumidor, que de forma prática pudesse mensurar o potencial de conversão das celebridades brasileiras.

Entre os modelos mencionados no início deste artigo, utilizamos o inaugural: o TEARS, criado por Shimp (2003). Como modelo teórico, propõe 5 parâmetros (conforme figura 1) para analisar a eficiência da celebridade como porta-voz do produto e sua influência no comportamento de compra do consumidor.

Fig. 1 - Os 5 parâmetros do Modelo TEARS, proposto por Shimp (2003) e adaptação do Modelo TEARS para o uso nesta pesquisa

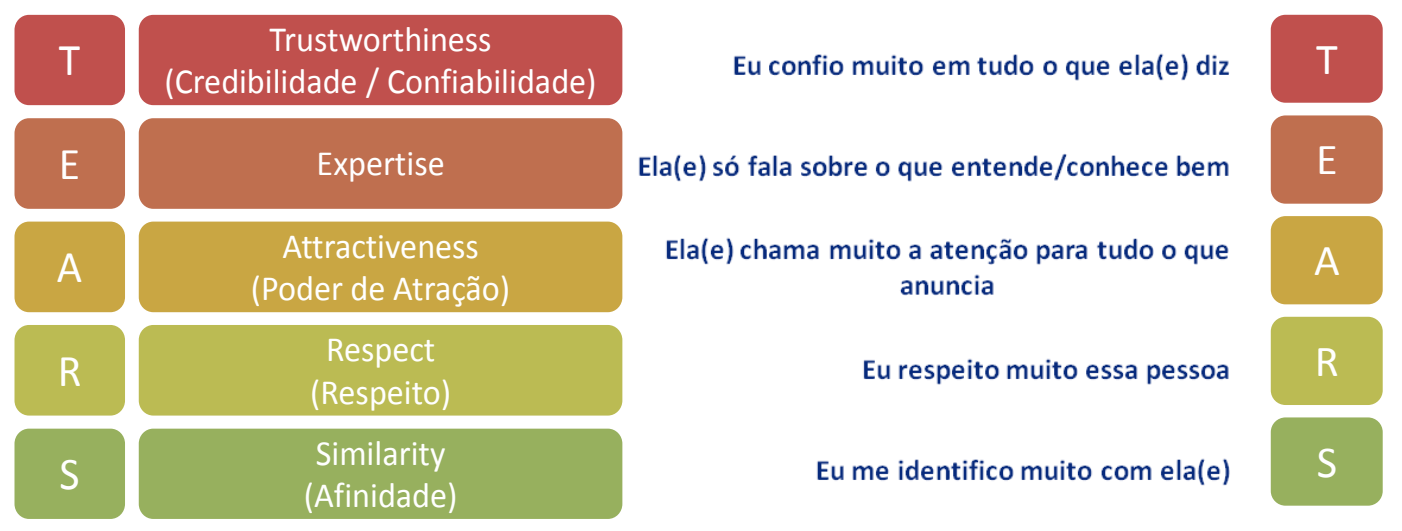

O autor propôs que, em síntese, os 5 parâmetros seriam capazes de fornecer diretrizes para a tomada de decisão de marketing quando o assunto era contratar uma celebridade. De acordo com Ericsson e Håkansson (2005 apud FREIRE, BEHLING e REINERT 2010: 15), a credibilidade está associada à tendência de acreditar ou confiar em alguém, nesta categoria inclui-se a confiabilidade (honestidade, integridade e fidedignidade) e a expertise (conhecimento ou habilidade que o endossante possui para ofertar o produto). O poder de atração é associado às habilidades intelectuais, atléticas, atributos da personalidade, estilo de vida, entre outros. Por sua vez, o respeito está ligado à qualidade de um endossante ser admirado por suas características pessoais e realizações. Considerando o último componente do modelo, um endossante apenas 
Celebridades, marcas e consumo: quais atributos dos famosos fortalecem um produto no mercado?

de Andrea Costa do Nascimento, Clodilde Perez, Diego Antonio de Oliveira e Karla Patriota Bronsztein

chamará atenção se houver um sentimento de similaridade, familiaridade ou, simplesmente, se o público-alvo gostar da celebridade.

Dessa forma, após constatarmos a coerência teórica do modelo proposto por Shimp (2003), era então necessário testá-lo entre as consumidoras do Brasil. Para isso, incorporamos na pesquisa questões relacionadas com os parâmetros do TEARS em relação às celebridades de interesse, apresentadas na adaptação listada na figura 1.

Com a adaptação do modelo TEARS, descobrimos que as celebridades brasileiras têm, de forma expressiva, destaque nos itens "respeito" (60\%) e "poder de atração" (56\%) perante os consumidores. Além de diagnosticarmos que a "confiança", presente na credibilidade e confiabilidade da celebridade, aumenta com a idade dos consumidores e que a classe $\mathrm{C}$, tida como a nova classe média brasileira, evidencia um maior reconhecimento dos fatores ligados aos endossantes célebres. (figura 2).

Fig. 2 - Percentuais por faixa etária, classe social e regiões brasileiras.

\section{MODELO TEARS}

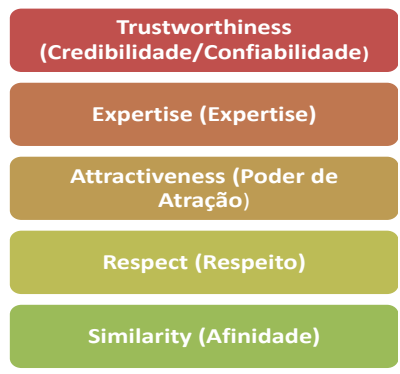

31

46
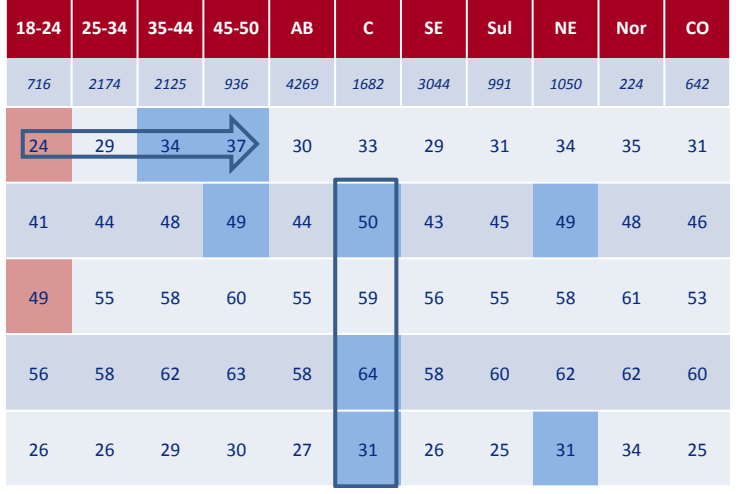

Tais percentuais evidenciaram que conhecer e trabalhar com as celebridades mais confiáveis são oportunidades para as marcas e produtos se diferenciarem no mercado e aumentarem o potencial de conversão das propagandas em vendas efetivas. Surge, dessa forma, entre as novas celebridades do ecossistema brasileiro, os "confiáveis e influentes" com destaque. Conforme as consumidoras, o simples reconhecimento de que alguém é uma celebridade não a torna uma pessoa confiável ou capaz de influenciar suas decisões sobre produtos e marcas. 
Celebridades, marcas e consumo: quais atributos dos famosos fortalecem um produto no mercado?

de Andrea Costa do Nascimento, Clodilde Perez, Diego Antonio de Oliveira e Karla Patriota Bronsztein

Por isso, personalidades como Ana Maria Braga ${ }^{11}$ e Glória Pires ${ }^{12}$, que não obtiveram destaque de forma espontânea nas entrevistas, despontam, de forma expressiva, quando o endosso é posto em questão. O poder de influenciar a compra revela ainda mais a força de Luciano Huck ${ }^{13}$, que traz sua mulher Angélica ${ }^{14}$ para a cena e, com maior importância, desponta a apresentadora Fátima Bernardes ${ }^{15}$.

Fig. 3 - Celebridades apontadas pelas consumidoras brasileiras - Ranking Top 5

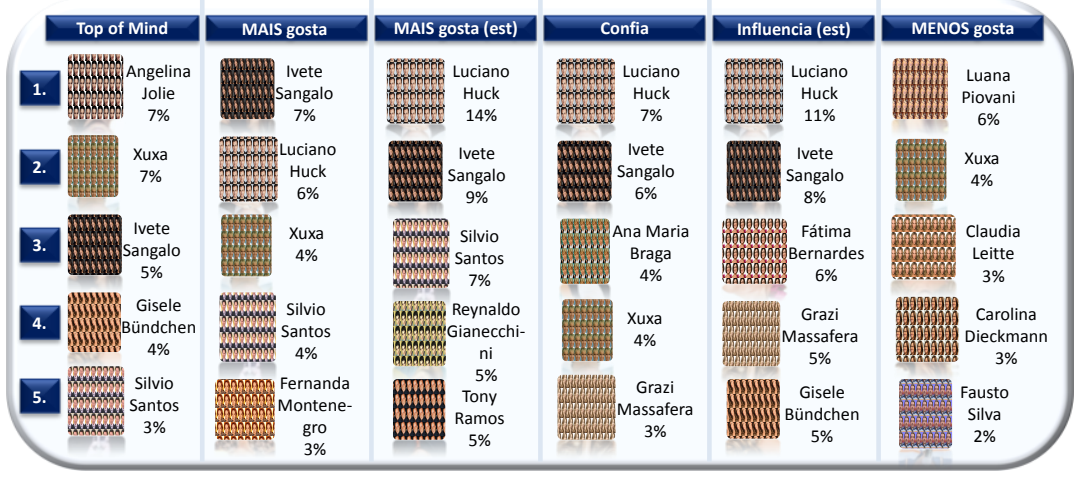

As descobertas da pesquisa também foram alicerçadas pelo agrupamento das consumidoras a partir dos seus níveis de envolvimento com o consumo de celebridades. Assim, segmentamos o mercado considerando como as consumidoras definem a influência que os famosos têm sobre seu comportamento e como relacionam celebridades com publicidades e marcas. Categorizamos tais envolvimentos a partir de três grupos: as "envolvidas", as "seguidoras" e as "indiferentes", conforme o quadro a seguir:

\footnotetext{
${ }^{11}$ Apresentadora de televisão e jornalista brasileira.

${ }^{12}$ Atriz brasileira. Conhecida por diversos papéis em telenovelas.

${ }^{13}$ Apresentador de Televisão. Participa de muitos anúncios publicitários.

${ }^{14}$ Apresentadora, atriz, cantora e modelo brasileira.

${ }^{15}$ Jornalista e apresentadora de televisão brasileira.
} 
Celebridades, marcas e consumo: quais atributos dos famosos fortalecem um produto no mercado?

de Andrea Costa do Nascimento, Clodilde Perez, Diego Antonio de Oliveira e Karla Patriota Bronsztein

Fig. 4 - Como as brasileiras se envolvem com o tema.

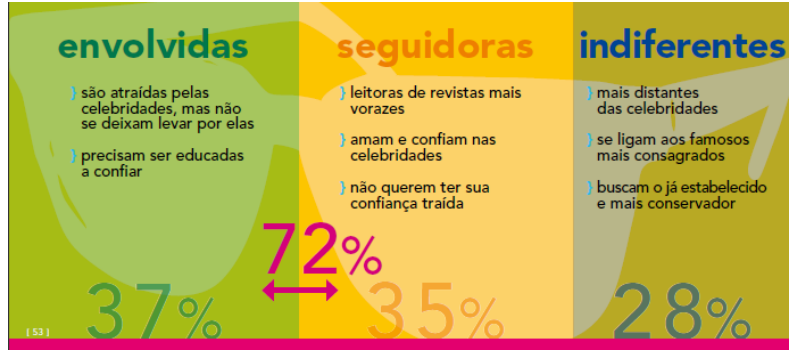

De forma mais ampla, a segmentação nos revelou que, utilizando uma figura famosa em uma campanha publicitária, apenas $28 \%$ das mulheres sentem-se mais distantes desse universo, enquanto $72 \%$ delas estão envolvidas com o tema.

\section{PRINCIPAIS DESCOBERTAS E APRENDIZADOS}

Diagnosticamos um grande potencial para publicidade na composição entre as “constelações" que, posteriormente agrupadas, classificamos como um ecossistema. Isso nos levou a considerar que a celebridade ser bem avaliada em todas as áreas estudadas - beleza, sucesso, comportamento e carisma - é grande parte do caminho para influenciar as brasileiras em suas decisões de consumo.

Entretanto, a intersecção de atributos das "constelações" sucesso, comportamento e carisma é a combinação com maior potencial para a publicidade, visto que concentram celebridades que se destacam em confiabilidade. Embora haja fortes celebridades que transitam nas constelações beleza ou beleza "mais" sucesso. De uma forma geral, a influência nas escolhas de marcas e produtos ganha importância quando sob o endosso de nomes que ocupam um lugar em outras constelações.

A partir da análise das constelações, verificamos que as consumidoras corroboram com os estudos teóricos sobre afinidade entre celebridade e produto. Assim, ao pensarem nas celebridades associadas a produtos de consumo, os consumidores tendem a analisar sempre se os atributos de imagem de ambos combinam (figura 5) e a rejeitar quando não há um 'casamento' positivo de atributos. Como os principais exemplos de rejeição estão: a) Uma celebridade muito sofisticada para um produto muito popular; b) Quando percebem que a celebridade não usaria realmente o produto; c) $\mathrm{O}$ estilo da celebridade não tem as características esperadas para o produto; além de 
Celebridades, marcas e consumo: quais atributos dos famosos fortalecem um produto no mercado?

de Andrea Costa do Nascimento, Clodilde Perez, Diego Antonio de Oliveira e Karla Patriota Bronsztein

que muitos acham que "Bons moços" e "Sem sal" não combinam tanto com automóveis, já que parece faltar potência para o carro.

Fig. 5 - Exemplos de atributos das celebridades associados a algumas categorias de produtos.

\begin{tabular}{|c|c|c|c|c|c|}
\hline CATEGORIA & Top1 & Top2 & Top3 & Top4 & Top5 \\
\hline Colônias e Perfumes & Carismático(a) & $\begin{array}{l}\text { Autêntico(a), } \\
\text { marcante }\end{array}$ & $\begin{array}{c}\text { Alegre, } \\
\text { Contagiante }\end{array}$ & Elegante & Charmosa (o) \\
\hline Calçados, sandálias e chinelos & Carismático(a) & $\begin{array}{c}\text { Alegre, } \\
\text { Contagiante }\end{array}$ & Talentosa (o) & $\begin{array}{l}\text { Autêntico(a), } \\
\text { marcante }\end{array}$ & Elegante \\
\hline Produtos para os cabelos & Carismático(a) & $\begin{array}{c}\text { Alegre, } \\
\text { Contagiante }\end{array}$ & $\begin{array}{l}\text { Autêntico(a), } \\
\text { marcante }\end{array}$ & Elegante & Charmosa (o) \\
\hline Vestuário (roupas, moda) & Carismático(a) & Elegante & $\begin{array}{l}\text { Autêntico(a), } \\
\text { marcante }\end{array}$ & $\begin{array}{c}\text { Alegre, } \\
\text { Contagiante }\end{array}$ & Talentosa (o) \\
\hline $\begin{array}{l}\text { Moda Intima (lingerie, meias e } \\
\text { pijamas) }\end{array}$ & Carismático(a) & Charmosa (o) & Elegante & $\begin{array}{l}\text { Seguro(a) de si, } \\
\text { auto-confiante }\end{array}$ & Alegre, Contagiante \\
\hline
\end{tabular}

O fato é que algumas descobertas relacionadas aos atributos merecem destaque: 1. Celebridades da constelação beleza endossam principalmente produtos de sedução e beleza; 2. O carisma atua como suporte e é sempre um complemento ao endosso; 3. Produtos de maior valor agregado são mais bem chancelados por celebridades da constelação sucesso; 4. As categorias de limpeza, saúde e alimentos estão altamente relacionadas à constelação comportamento.

Portanto, como era de se esperar, o potencial das "constelações" varia conforme a categoria dos produtos. A esfera da beleza impacta mais produtos para o corpo, rosto, moda íntima, que embelezam e seduzem; combinada com carisma é o melhor endosso para categorias como perfume e maquiagem.

Celebridades que estão na esfera do sucesso são importantes para divulgar produtos de maior valor agregado (carro, celular, banco etc.). Comportamento, isoladamente, pode chancelar produtos de limpeza (casa e higiene bucal) e bebidas não alcoólicas. Estar posicionada na junção de carisma+sucesso+comportamento potencializa a associação com bebidas alcoólicas, relógios e joias, produtos que relacionam poder e sedução.

Em paralelo, obtivemos outros aprendizados muito importantes, a saber:

a) Beleza não é tudo. Embora a beleza física seja catalizadora da atenção das consumidoras e característica verificada para a maioria dos famosos estimulados, não é ponto decisivo na definição de uma celebridade, nem determina afetividade ou maior proximidade em relação a ela. Muitas 
Celebridades, marcas e consumo: quais atributos dos famosos fortalecem um produto no mercado?

de Andrea Costa do Nascimento, Clodilde Perez, Diego Antonio de Oliveira e Karla Patriota Bronsztein

celebridades importantes, amadas e confiáveis não trazem consigo esse atributo.

b) Celebridade não se faz só na novela. As celebridades mais lembradas e amadas não se restringem aquelas que estão ou estiveram recentemente em novelas, nem se restringem a atrizes e atores. Apresentadores, cantores, modelos estão presentes nas posições mais tops.

c) O Modelo TEARS indica oportunidade na definição e uso de celebridades mais confiáveis e afinadas com as consumidoras. Atração e respeito são os fatores mais presentes entre as celebridades. A relação entre as brasileiras e as celebridades é fundada na atração (a partir da beleza ou do poder, da riqueza) e no respeito (calcado na admiração pelo sucesso profissional, por exemplo), mas não alcança níveis satisfatórios de confiança e identificação.

d) Confiança - assim como a afinidade - está baseada no "efeito espelho". $\mathrm{O}$ fato de que o perfil das consumidoras é similar ao das celebridades em quem confiam, deve se juntar ao fato de que as mais jovens declaram-se as mais influenciáveis pelas celebridades, que claramente são, na maioria dos casos, jovens personalidades.

e) Entre as mais jovens: não é preciso confiar para seguir. As brasileiras mais jovens mostram traços atitudinais que remetem a uma relação mais fluida (menos sólida, mais pós-moderna) com as celebridades, com expectativa mais baixa de coerência (de uso de produtos anunciados, por exemplo) e menos calcada em confiança, mas ainda assim são as mais interessadas em saber sobre seus usos, suas modas, identificando-se mais com elas e admitindo a maior influência delas em suas escolhas. Para este público, a beleza e a popularidade contam mais na definição de uma celebridade e suas referências midiáticas ampliam esse universo, onde estão mais presentes popstars como Beyonce e Madonna.

f) Entre as mais maduras: buscam coerência para confiar. Esboçando um quadro antagônico com as mais jovens, as brasileiras mais velhas são as que mais valorizam os bons exemplos de vida e os valores na definição das celebridades. E, embora sejam as que mais declaram confiar em 
Celebridades, marcas e consumo: quais atributos dos famosos fortalecem um produto no mercado?

de Andrea Costa do Nascimento, Clodilde Perez, Diego Antonio de Oliveira e Karla Patriota Bronsztein

celebridades, não se identificam nem se deixam influenciar por elas, sendo indiferentes aos seus hábitos e modismos. Por depositarem alguma confiança nas celebridades, são as que mais se importam com a coerência entre o que a celebridade anuncia ou endossa e o que ela realmente usa.

g) Dentre os segmentos de consumidoras, o de maior potencial para o consumo de celebridades na publicidade é o que se chamou As Seguidoras. As Seguidoras (35\%): formado pelas leitoras de revistas mais vorazes, amam e confiam nas celebridades e não querem ter sua confiança traída. (Como parâmetros do TEARS: Confiança e Afinidade); As Indiferentes (28\%): as mais distantes e impassíveis às celebridades, se ligam aos famosos mais consagrados, buscando o já estabelecido e mais conservador. (Como parâmetro do TEARS: Expertise); As Envolvidas (37\%): são atraídas pelas celebridades, mas não se deixam levar por elas, precisam ser educadas a confiar. (Como parâmetro do TEARS: Atratividade).

h) A Revista é o veículo privilegiado de elevação dos parâmetros TEARS. Leitoras de revistas reconhecem tais parâmetros, especialmente confiança e afinidade nas celebridades. Consumidoras associam a revista às celebridades definindo-a como sendo o meio mais agradável de vê-las e uma forma de melhorar a imagem do produto e da marca anunciados. Entre as leitoras de Contigo! e Caras destaca-se o fato de serem mais ligadas nos exemplos de vida e valores. Para estas, as revistas cumprem seu papel socializador/ "educativo". Além de que as leitoras de revista de celebridades são mais suscetíveis a consumir produtos/serviços endossados por celebridades.

\section{CONSIDERAÇÕES FINAIS}

A pesquisa nos revelou diversos aspectos relacionados às percepções das consumidoras quando o tema é celebridades endossando produtos e serviços. Como exemplo significativo está o fato de que sete em cada dez consumidoras esperam que a celebridade, além de ser bem conhecida, dê um bom exemplo para a sociedade, o que 
Celebridades, marcas e consumo: quais atributos dos famosos fortalecem um produto no mercado?

de Andrea Costa do Nascimento, Clodilde Perez, Diego Antonio de Oliveira e Karla Patriota Bronsztein

revela a referencialidade do "modelo heróico". Nesse sentido, também foi revelado que beleza e auto identificação não são características citadas pela maioria.

Quase 500 nomes foram lembrados espontaneamente. Nessa extensa lista houve uma concentração máxima de lembrança de apenas 7\%, e embora a metade das menções seja de atrizes ou atores, os Top Five não estão nas novelas e tem ocupações variadas, como apresentadores, cantores, modelos.

Leitoras das revistas Contigo! e Caras reforçam ainda mais os aspectos do exemplo $(75 \%)$ e dos valores $(70 \%)$, estas são mais socializadas no tema e, portanto, evidenciam um maior nível de exigência. As mais jovens estão mais ligadas em fama e beleza e as mais velhas "pesam a mão" no aspecto moral: melhores exemplos e valores.

Ao final da etapa quantitativa conseguimos produzir um simulador que indica os atributos que a celebridade deve ter para endossar determinada categoria, na ótica dos consumidores. Partimos da mesma lista de atributos utilizada para caracterizar as celebridades, podendo inclusive se chegar à indicação de um ou mais nomes para representar uma marca ou um produto/serviço.

\section{REFERÊNCIAS BIBLIOGRÁFICAS}

ALSMADI, Sami. "The Power of Celebrity Endorsement in Brand Choise Behavior: An Empirical Study of Consumer Attitudes", in Journal of Accounting - Business \& Management, v. 13, 2006, p 69-84.

ANDRADE, J.; MAZZON, J., KATZ, S. "Você viu o Vídeo do Ronaldinho? Uma Reflexão a Respeito da Associação entre Marcas e Celebridades e o Uso do Marketing Viral como Ferramenta de Comunicação de Marketing”. In: Encontro Nacional da Anpad - Associação Nacional de Pós-graduação e Pesquisa em Administração, XXX EnANPAD, 2006, Rio de Janeiro - RJ. Anais... Rio de Janeiro: EnANPAD, 2006.

BOORSTIN, D. J. The image: a guide to pseudo-events in America. NY: Atheneum, 1962.

CAMPBELL, J. O herói de mil faces. São Paulo. Cultrix. 1993.

DALBÓ, G.; MILAN, S.G; TONI, D. O Endosso por Celebridade e a Gestão da

Imagem da Marca: Evidências Empíricas a partir do Estudo da Marca 
Celebridades, marcas e consumo: quais atributos dos famosos fortalecem um produto no mercado?

de Andrea Costa do Nascimento, Clodilde Perez, Diego Antonio de Oliveira e Karla Patriota Bronsztein

Ipanema Gisele Bündchen. Trabalho apresentado no XIII Seminários em Adminstração, realizado em setembro de 2010.

ERICSSON, L.; HÅKANSSON, E. Athletes as Celebrity Endorsers. Case Studies

from Sweden. 85 : (Master's Thesis) International Business Administration and Social Sciences. Division of Industrial marketing and e-commerce. Suécia, 2005.

Disponível em: <http://epubl.luth.se/1404-5508/2005/049/LTU-SHU-EX05049-SE.pdf $>$. Acesso em: 18 Jan. 2013.

FREIRE, R., BEHLING, H. P., REINERT J. "Endosso de Celebridades: Uma Análise Baseada na Complementaridade de Modelos Teóricos", in Anais... XI Congresso de Ciências da Comunicação na Região Sul - Novo Hamburgo - RS 17 a 19 de maio de 2010.

HELAL, R. "Cultura e Idolatria: ilusão, consumo e fantasia", in ROCHA, E. (org.) Cultura e Imaginário: interpretação de filmes e pesquisa de ideias. Rio de Janeiro, Mauad, 1998.

HOLT, D. B. How brands become icons: the principles of cultural branding. Cambridge: Harvard Business School Press, 2004.

JUNG, C. G. Chaves-resumo das obras completas Jung/ Carl Gustav Jung; [coordenação editorial] Carrie Lee Rothgeb, National Clearinghouse for Mental, Health Information; tradução Arlene Ferreira Caetano]. São Paulo: Editora Atheneu, 1998.

MARK, M.; PEARSON, C. The hero and the outlaw: building extraordinary brands through the power of archetypes. New York: McGraw-Hill, 2002.

MATTA, J. O. S. "Cultura da mídia e celebridades (midiáticas) do contemporâneo: Madonna e Avril Lavigne”, in Anais... II Colóquio Binacional Brasil-México de Ciências da Comunicação. De 01 a 03 de abril de 2009 - São Paulo - Brasil.

MORIN, E. As estrelas - mito e sedução no cinema. Rio de Janeiro: José Olympio, 1989.

PATEL, P. "Impact of Celebrity Endorsement on Brand Acceptance". In The Icfai University Journal of Consumer Behavior, $\mathrm{n}^{\circ}$ 1, v. 4, 2009.

PENA, F. "Celebridades e heróis no espetáculo da mídia", in Revista Brasileira de Ciências da Comunicação. $n^{\circ}$ 1, vol. XXV, São Paulo, janeiro/junho de 2002 Disponível em: 
Celebridades, marcas e consumo: quais atributos dos famosos fortalecem um produto no mercado?

de Andrea Costa do Nascimento, Clodilde Perez, Diego Antonio de Oliveira e Karla Patriota Bronsztein

<http://portcom.intercom.org.br/revistas/index.php/revistaintercom/article/viewFile/447 /416>. Acesso em: 18 jan. 2013.

SILVEIRA, R. ; MARCON, R. ; NASCIMENTO, H. "Se Ele Usa, Eu Uso: Um Estudo Sobre a Contribuição do Endossamento de Celebridades aos Valores Econômicos, Financeiros e de Mercado das Empresas de capital aberto no Brasil", in: Encontro Nacional da Anpad - Associação Nacional de Pósgraduação e Pesquisa em Administração, XXXI EnANPAD, 2007, Rio de Janeiro - RJ. Anais... Rio de Janeiro: EnANPAD, 2007.

SHIMP, T. Propaganda e promoção: aspectos complementares da comunicação integrada de marketing. Porto Alegre: Bookman, 2003.

Artigo submetido: 16/04/2013

Artigo aprovado: 23/09/2013 